\title{
WestVirginiaUniversity
}

THE RESEARCH REPOSITORY @ WVU

Graduate Theses, Dissertations, and Problem Reports

2012

\section{Impulsivity and Suicidal Ideation or Attempt in Younger and Older Adults}

Elizabeth C. Price

West Virginia University

Follow this and additional works at: https://researchrepository.wvu.edu/etd

\section{Recommended Citation}

Price, Elizabeth C., "Impulsivity and Suicidal Ideation or Attempt in Younger and Older Adults" (2012). Graduate Theses, Dissertations, and Problem Reports. 163.

https://researchrepository.wvu.edu/etd/163

This Dissertation is protected by copyright and/or related rights. It has been brought to you by the The Research Repository @ WVU with permission from the rights-holder(s). You are free to use this Dissertation in any way that is permitted by the copyright and related rights legislation that applies to your use. For other uses you must obtain permission from the rights-holder(s) directly, unless additional rights are indicated by a Creative Commons license in the record and/ or on the work itself. This Dissertation has been accepted for inclusion in WVU Graduate Theses, Dissertations, and Problem Reports collection by an authorized administrator of The Research Repository @ WVU.

For more information, please contact researchrepository@mail.wvu.edu. 
Impulsivity and Suicidal Ideation or Attempt in Younger and Older Adults

\author{
Elizabeth C. Price
}

\author{
Thesis Submitted to the \\ Eberly College of Arts and Sciences \\ at West Virginia University \\ in partial fulfillment of the requirements \\ for the degree of \\ Doctor of Philosophy \\ In \\ Psychology
}
Amy Fiske, Ph.D., CBSM, Chair
Barry Edelstein, Ph.D.

Karen G. Anderson, Ph.D.

Department of Psychology

Morgantown, West Virginia

2012

Keywords: Suicidal behavior; Older adults; Impulsivity

Copyright 2012 Elizabeth C. Price 


\section{ABSTRACT \\ Impulsivity and Suicidal Ideation or Attempt in Younger and Older Adults}

\section{Elizabeth C. Price}

Rates of suicidal behaviors vary over the lifespan, but little research has focused on developmental aspects of suicidal behaviors and associated risk factors. Previous studies suggest that young people who attempt or die by suicide are likely to be generally impulsive. 108 community-dwelling older adults age 60 and older and 498 undergraduate students ages 18-30 completed the Center for Epidemiological Studies - Depression Scale, the Barratt Impulsivity Scale, and the Suicidal Behaviors Scale - Revised. The hypothesis was that the relation between impulsivity and suicidal ideation or attempt, in the context of depressive symptoms, would be stronger in younger adults than in older adults. However, a three-way interaction between impulsivity, depressive symptoms, and age group to predict suicidal behaviors was not statistically significant. Contrary to expectations, impulsivity was not related to suicidal behaviors in younger adults, controlling for depressive symptoms. Exploratory analyses found that older adults were more likely than younger adults to report suicide attempts with a greater intent to die. The implications for treatment and future directions are discussed. 


\section{TABLE OF CONTENTS}

Page

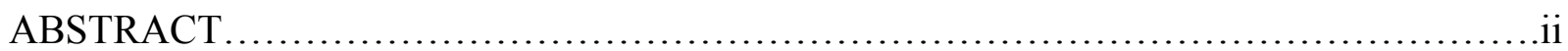

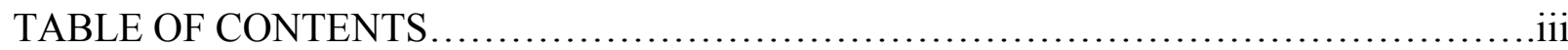

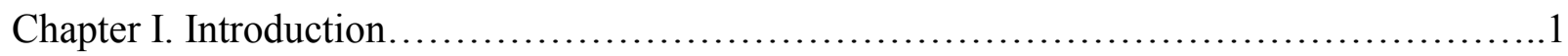

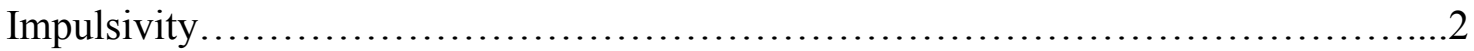

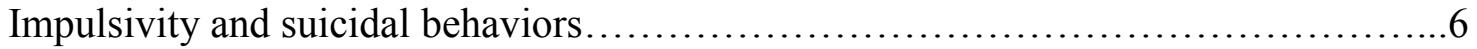

Age, impulsivity, and suicidal behavior........................................ 11

Gender, impulsivity, suicidal behavior.......................................... 15

Statement of the problem.....................................................

Chapter II. Method.................................................................... 19

Participants and procedure....................................................

Measures.................................................................. 21

Chapter III. Results......................................................... .24

Descriptive statistics................................................... 24

Missing data and assumptions for linear regression............................. 25

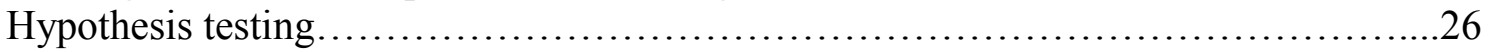





Conclusions and Future Directions..............................................

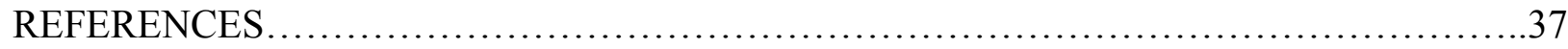

TABLE 1: Participant Characteristics ............................................49

TABLE 2: Descriptive Statistics for Study Variables...................................50

TABLE 3: Intercorrelations among Study Variables for All Participants $(N=579) \ldots \ldots \ldots \ldots . . .51$

TABLE 4: Intercorrelations among Study Variables for Younger $(n=474)$ and Older $(n=105)$

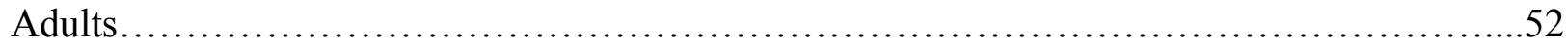

APPENDIX A: Suicidal Behaviors Questionnaire - Revised............................53

APPENDIX B: Barratt Impulsiveness Scale.......................................55

APPENDIX C: The Centers for Epidemiological Studies - Depression Scale...............57 
Impulsivity and Suicidal Ideation or Attempt in Younger and Older Adults

Adults age 65 and older have one of the highest rates of suicide of all age groups, with 14.8 men and women out of 100,000 dying by suicide in 2009 , compared to the overall rate of 12.0 out of 100,000 (McIntosh, 2012). Individuals over age 85 have an even higher rate of 15.6 out of 100,000. Despite these relatively high prevalence rates, most suicide research has focused on adolescent and college-age men and women, who have a relatively lower risk. Identifying risk factors for suicide is important to identify those most in need of intervention, especially in older adults, who are less frequently treated by mental health professionals compared to other adults (Bognerde, de Vries, Maulik, \& Unützer, 2009). Demographic information (e.g., gender and ethnicity), the presence of a psychiatric disorder, and affective states such as hopelessness provide some predictive value, but many individuals who possess these qualities do not die by suicide, so other factors must be relevant (Conner, Duberstein, Conwell, \& Caine, 2003; Mann, Waternaux, Haas, \& Malone, 1999).

Impulsivity, or acting without regard for long-term consequences, is a likely risk factor for suicide. It has been studied extensively in young and middle adult samples, but not as thoroughly in older adults samples (Brezo, Paris, \& Turecki, 2006; Oquendo et al., 2004). We cannot assume that risk factors for younger adults and older adults are the same, as people in these different age groups who attempt or die by suicide vary in the psychopathology they display, lethality and methods used, and other factors associated with suicidal behavior (Conwell \& Brent, 1996; Fiske, Wetherell, \& Gatz, 2009; Turecki, 2005).

Most research examining the relation between impulsivity and suicidal behaviors has used deaths by suicide and suicide attempts as outcomes. Few studies have examined the relations among age, impulsivity, and suicidal ideation - thinking about and planning for suicide. 
Suicidal ideation, suicide attempts, and death by suicide are related. Terms such as -suicidal behaviors" or -suicidality" may encompass more than one when it is appropriate to do so. However, each have their own epidemiology and associated risk factors. We cannot assume that

higher rates of death by suicide among impulsive individuals automatically represent differences in suicidal ideation, for example. We can, however, use previous research finding about some types of suicidal behavior to form testable hypotheses about factors related to other types of suicidal behavior. Research that distinguishes among age groups and types of suicidal behavior will be most useful to clinicians and researchers in the future.

The current project was designed to extend the research on impulsivity and suicidal behaviors from younger adults to older adults. It examined outcomes of self-reported suicidal ideation, or thinking about suicide, and suicide attempts. In addition, the current project examined the role of gender in an exploratory fashion. In order to accomplish these goals, I first define impulsivity and how it has been studied related to suicide. Then, I discuss the relations between impulsivity and suicidal behaviors. There is limited literature examining impulsivity and suicidal ideation and attempts, so findings about death by suicide were used make predictions about suicidal ideation and attempts. This paper highlights known age differences in the relations between impulsivity and suicidal behavior and conclude with a discussion of the role of gender in these relations.

\section{Impulsivity}

Impulsivity has been defined in various ways, contributing to some disagreement and confusion about the construct (Gvion \& Apter, 2011). A useful biopsychosocial definition of impulsivity incorporates biological and behavioral patterns resulting in -apid, unplanned reactions to internal or external stimuli," as well as disregard for long-term personal and social 
consequences (Möller, Barratt, Dougherty, Schmitz, \& Swann, 2001, p. 1784). Impulsivity may not always be harmful or maladaptive as focus on short-term consequences does not always result in poor outcomes. Impulsivity may be conceptualized as a personality trait" or temperament," referring to stable patterns of reactivity (Brezo et al., 2005). On the other hand, laboratory tasks, such as delay-discounting, can determine states during which humans display more or less impulsivity (e.g., while under the influence of substances or in a manic state) (Giegling et al., 2009; Maser et al., 2002). Risk-taking, non-planning, and tiveliness,” or high activity levels, are factors that have traditionally been conceptualized as comprising impulsivity (Eysenck, 1993; Eysenck \& Eysenk, 1977). High activity levels or rapid, unplanned reactions refer to thoughts (e.g., not being able to focus) as well as observable behavior (Barratt, 1965; Eysenck \& Eysenk, 1977; Whiteside, Lynam, Miller, \& Reynolds, 2005). Impulsive individuals are less able to defer gratification and have difficulty regulating their emotions and actions, perhaps because they do not plan for the future and experience rapid changes in behavior and thoughts (Gvion \& Apter, 2011).

Impulsivity may be operationalized using self-report, observation, or behavioral laboratory measures (Möller et al., 2001). Measures such as the Barratt Impulsiveness Scale-11 (BIS-11) ask questions about general tendencies, without a specified time frame. The BIS-11 has been used extensively with a wide variety of participants (Stanford et al., 2009). Other self-report measures, including those developed by Eysenk and Eysenk (1977) (e.g., the Eysenck Impulsiveness Scale), have attempted to distinguish between functional and dysfunctional impulsivity. Subsets of questions from the Temperament and Character Inventory, the Revised NEO Personality Inventory and other comprehensive personality measures are also used to examine impulsivity and its correlates (Giegling et al., 2009; Maser et al., 2002; Whiteside et al., 
2005). The UPPS Impulsive Behavior Scale is a newer measure that focuses on the etiology and goals of the impulsive acts (Whiteside et al., 2005). Each measure emphasizes different facets of impulsivity. A singular operational definition of impulsivity is surprisingly difficult to find or determine (Gvion \& Apter, 2011). However, the core aspects of risk-taking, non-planning, and some type of elevated motor or cognitive activity level are generally represented in self-report measures.

Impulsivity may also be measured in human and non-human animals using specific tasks in the laboratory. Delay discounting requires participants to make a choice between receiving a small amount of a reinforcer sooner or a larger amount later (Dombrovski et al., 2011; Odum, 2011). This task represents a choice of immediate reinforcement over delayed, larger reinforcement. As indicated above, because different situations may be associated with different levels of impulsivity, there is skepticism about impulsivity as a stable facet of personality (Odum, 2011). However, recent research has determined that individuals' impulsivity, as measured by delay-discounting, is similar over ranges of situations involving money, food, and drugs of abuse (Odum, 2011). Odum concluded that because delay-discounting performance is stable over time but subject to predictable developmental change, heritable, and associated with identifiable brain activity and structures, it is likely an enduring predisposition or trait." Performance on delay-discounting tasks has been found to correlate with self-reports of general impulsivity on the BIS, $r=.53$ (Mitchell, Fields, D’Esposito, \& Boettiger, 2005). In studies where this relation was not found, it may be the result of small sample size due to the targeting of specific clinical populations, or because the BIS measures several facets of impulsivity (motor, non-planning, and attentional impulsiveness), while delay discounting is highly specific (Odum, 2011; Swann et al., 2005). 
For the identification of impulsivity to be clinically useful, clinicians must be able to identify clients who are particularly or pathologically impulsive: demonstrated impulsivity may vary over specific situations or states, but is likely that there are some individuals who are generally more impulsive than others. Although impulsivity may not always be maladaptive, impulsivity is a symptom associated with many serious psychiatric disorders such as Bipolar I Disorder, substance dependence, and Borderline Personality Disorder, three disorders with high suicide rates (Swann et al., 2005; Mitchell et al., 2005; Möller et al., 2001). Impulsivity may confer risk for these disorders or may be a resulting visible symptom of these disorders. (Brezo et al., 2006; Moeller et al., 2001). Overall, studying impulsivity is more specific than studying a group of individuals with a certain psychiatric diagnosis, who may or may not share the same symptoms, behaviors, or biological markers.

Impulsivity and suicidal behaviors are thought to both be associated with low serotonin and dopamine levels and function in the brain, and thus may be related on a biological level (Brezo, et al. 2006; Conner et al., 2003). More specifically, there is evidence for the genetic transmission of suicide through the serotonin receptor and tryptophan hydroxylase genes (Joiner, Brown, \& Wingate, 2005). Reduced 5-HIAA, a metabolite of serotonin, in cerebrospinal fluid has been associated with impulsive individuals who attempt suicide. These individuals have also been found to have a blunted prolactin response to fenfluramine challenge, evidence of reduced stimulation of serotonin (Joiner et al., 2005). Administration of selective serotonin reuptake inhibitors has been associated with reduced self-reported and demonstrated impulsivity and aggression in males with criminal backgrounds (Butler et al., 2010; Cherek, Lane, Pietras, \& Steinberg, 2002). Similarly, administration of d,l-fenfluramine, which releases serotonin and dopamine, reduced impulsive responding in males with conduct disorder (Cherek \& Lane, 2000). 
Suicidal and impulsive individuals show decreased serotonin transporter binding in the ventral prefrontal cortex, while individuals with depression only do not (see Joiner et al., 2005 for review). Overall, the available evidence suggests that suicidal behavior and impulsive behavior share biological markers related to low serotonin.

It should be noted that the literature on impulsivity and suicide also includes findings on reactive aggression." This related construct is also measured by self-report and has been a focus of study for major suicide research groups (Brezo et al., 2006; Conner, Conwell, Duberstein, \& Eberly, 2004). Reactive aggression is an impulsive, often non-rational reaction to a sudden, perceived threat (Gvion \& Apter, 2011). In contrast, impulsivity is not always a response to a threat but may lead an individual to act without planning or considering the consequences, or to generally be uninhibited (McGirr, Paris, Lesage, Renaud, \& Turecki, 2007). Aggression may be impulsive or planned, and an impulsive act may or may not be aggressive (Garcia-Forero, Gallardo-Pujol, Maydeu-Olivares, \& Andres-Pueyo, 2009). These researchers postulate that impulsive and aggressive acts, including suicide, stem from the same disturbances in serotonin levels and receptor activity (Conner et al., 2003). A pattern of reactive aggression may be indicative of high impulsivity and higher risk for suicide. This construct is ubiquitous in discussions of impulsivity and suicidal behaviors (Giegling et al., 2009).

\section{Impulsivity and suicidal behaviors}

Death by suicide and attempted suicide. Individuals who die by suicide or attempt suicide are more likely to be impulsive than non-suicidal individuals, even when controlling for the presence of a mood disorder. Dumais et al. (2005) examined males who were depressed and died of suicide and compared them to depressed living men using interviews with family and friends, including the BIS-11 and other measures. There were significantly more impulsive men 
in the suicide group than in the non-suicide group. Maser et al. (2002) conducted a 14-year prospective study of individuals with severe manic, schizoaffective, and depressive episodes. Clinical factors (e.g., severity of affective symptoms) were most important for predicting suicide within one year of study intake. However, items from personality measures indexing impulsivity, combined with other personality factors, predicted death by suicide from two to 14 years after study intake with $82.3 \%$ specificity and $73.9 \%$ sensitivity, higher levels of specificity and sensitivity than clinical factors. Mann et al. (1999) and Pezawas et al. (2002) found similar levels of objectively measured depression in psychiatric inpatients who had attempted suicide and those who had not. Impulsivity, as defined by scores on the BIS, distinguished the two groups and was a significant predictor of suicide attempt status.

Previous research suggests that overt suicidal behavior is the result of mood disturbance plus an increased tendency to act on suicidal thoughts, such as that conferred by greater impulsivity (Mann et al., 1999; Pezawas et al., 2002). More specifically, impulsivity may moderate the relation between mood problems such as major depression and suicidal behaviors (Oquendo et al., 2004; Swann et al., 2005). In these studies, a stress-diathesis model is suggested: depressed individuals who either did or did not attempt suicide had nearly identical clinician-rated depression, but could be distinguished by impulsive tendencies and other factors (Mann et al., 1999; Oquendo et al., 2004; Pezawas et al., 2002).

For example, Anestis and Joiner (2011) tested a facet of impulsivity, negative urgency, or the tendency to act rashly in an attempt to reduce feeling of negative affect," and its relation to history of suicide attempts in young women (p. 262). Joiner's interpersonal-psychological theory of suicide states that perceived burdensomeness, thwarted belongingness, and acquired capacity to inflict self-harm are necessary factors for death by suicide (Joiner, 2005). In this study, these 
three variables significantly predicted number of lifetime suicide attempts for participants above the $50^{\text {th }}$ percentile for negative urgency, but not for those low in the construct.

Surprisingly, impulsivity does not necessarily confer risk by making individuals more likely to make a rash decision to hurt themselves. Several studies have examined the impulsivity of a suicide attempt (i.e., if the person planned it in advance) as well as collecting information about self-reported general impulsivity. Baca-Garcia et al. (2005) examined BIS-11 scores and the impulsiveness of a suicide attempt in 278 suicide attempters and found that the two types of impulsivity were not significantly correlated, $r=.11$. Wyder and De Leo (2007) examined individuals who had attempted suicide and found that even among a group who identified their attempt as impulsive, most had at least suicidal thoughts before the attempt (i.e., some level of planning for the attempt). There was no difference in reported general impulsivity (as measured by the Plutchik Impulsivity Scale) between those who made an impulsive attempt and those who made a non-impulsive attempt.

What accounts for the difference in suicide attempts and deaths between impulsive and non-impulsive individuals? Anestis and Joiner (2011) concluded that negative urgency, a particular type of impulsivity, greases the wheels of suicidal ideation" and may contribute to greater acquired capacity to inflict deadly self-harm through repetition of -painful and provocative" acts. (p. 263 and 268). In other words, the relation between impulsivity and suicidal behavior may not be direct, and therefore not be represented in impulsive suicide attempts. Rather, impulsive individuals are more likely to be involved in activities throughout their life that increase their ability for self-harm by slowly habituating them to danger and pain (Joiner, 2005). The interpersonal-psychological theory of suicide states that overwhelming negative affect and life experiences (e.g., feeling like a burden and feeling disconnected from others) are 
necessary before an individual will desire suicide (Joiner, 2005). Perhaps individuals who die by suicide have accumulated experiences that, when combined with depressed mood, contribute to their ability to take their own life (Witte et al., 2008). Impulsivity in the absence of these negative states would likely not result in suicidal behavior.

Suicidal ideation. Impulsivity has most often been conceptualized as increasing risk for overt suicidal behavior, but verbal or written reports of thoughts or plans for suicide - suicidal ideation - may also be related to impulsivity. Individuals with an enduring predisposition to commit impulsive acts may be more sensitive to short-term consequences. They may think of suicide as a way out" more quickly or more often than less impulsive individuals, in order to escape uncomfortable emotions. It is conceivable that, to the extent that the individual feels relief and escape from negative affective states when thinking about suicide, suicidal thoughts are negatively reinforcing in the moment. Research supports the idea that some individuals engage in unhealthy efforts to regulate negative mood (Tice, Bratslavsky, \& Baumeister, 2001). Thinking about suicide as a way to cope may be unhealthy because it competes with other, more adaptive behaviors (i.e. problem solving or experiencing pleasant events). It represents a choice for immediate reinforcement over delayed, larger reinforcement.

A few studies have explicitly examined the relation between self-reported suicidal ideation and impulsivity. In a study examining self-reported -dysfunctional impulsivity" and suicidal ideation in Australian prisoners, Dear (2000) found no relation between suicidal ideation and impulsivity after controlling for scores on the Beck Depression Inventory, $r=.01$. However, more compelling evidence was found by both Pezawas et al. (2002) and Mann et al. (1999), who found that impulsivity predicted suicidal ideation, distinguishing between two groups of similarly depressed inpatients. Mann et al. (2002) and Pezawas et al. (1999) both found modest 
but significant correlations between suicidal ideation and aggression-impulsivity among psychiatric patients, $r=.28$ and .39 , respectively.

Conner, Meldrum, Wieczerek, Duberstein, and Welte (2004) examined suicidal ideation and impulsivity, as measured on the Psychopathic States Inventory, in a community sample of 625 males ages $15-20$ over three years. A large portion of the sample was youth identified as having delinquent patterns of behavior. The authors conceptualized impulsivity and irritability as components of reactive aggression." Interestingly, impulsivity was associated with suicidal ideation even after controlling for aggression and its correlates (e.g., drug and alcohol use and psychopathy) $(\mathrm{OR}=1.15)$.

Only one study has explicitly examined self-reported suicidal ideation and impulsivity in middle-aged to older adults. Neufeld and O'Rourke (2009) examined impulsivity and suicidal ideation in adults 49 and older (average age of 68) with any suspected suicide risk, serious depressive symptomatology, a combination of affective disorder and physical health problems, or scores in the clinical range on a standard depression assessment. They found that impulsivity was significantly associated with suicidal ideation in this sample, although modestly, $r=.33$. This is the only study identified that explicitly examined self-reported suicidal ideation and selfreported impulsivity on the BIS-11 in living older adults.

In addition, research with older adults using behavioral tasks supports the relation between suicidal ideation and impulsivity, independent of depression. Dombrovski et al. (2011) found different levels of delay-discounting, described earlier, in adults over 60 who were included in one of four categories: a control group, those who reported depression without suicidal ideation, those who reported serious suicidal ideation, and those who had attempted suicide. The researchers used a choice task in which participants could make a choice between a 
smaller amount of cash sooner, or a larger amount later. Individuals who reported suicidal ideation demonstrated more impulsivity on this task than control subjects and depressed, nonsuicidal participants.

Continued research on the relation between impulsivity and suicidal ideation is important for several reasons, and previous researchers have called for more work in this area (Brezo et al., 2006; Gvon \& Apter, 2011). Thinking about and planning for suicide - suicidal ideation - is a clear risk factor for suicide attempts and completions (e.g., Mann et al., 1999; Wyder \& De Leo, 2007). Suicidal ideation is much more widespread than suicide attempts or deaths by suicide. Knowing who is likely to think about suicide may help prevention efforts for attempts or death by suicide because intervention can occur earlier, before any physical harm (Mann et al., 1999). Consistent with the interpersonal-psychological theory of suicide, continued rumination or mental rehearsal about suicide may also increase acquired capacity to die by suicide (Joiner, 2005). Understanding how impulsivity contributes to suicidal ideation and acquired capacity over the lifespan will help to refine Joiner's theory. Serious suicidal ideation itself may be a target for intervention and represent difficulties regulating emotions and treatable mental disorders such as Major Depressive Disorder or Borderline Personality Disorder (American Psychological Association, 2000).

\section{Age, impulsivity, and suicidal behavior}

There is evidence to suggest that younger adults are generally more impulsive than older adults and that younger adult suicide is more highly related to impulsivity than older adult suicide. Willems, Linden, and Marczewski (2003) administered the Eysenk Impulsiveness Scale to young adults age 18 to 30 and older adults age 60 to 70 . Younger adults scored significantly 
higher on all factors of the scale. On delay-discounting tasks, older adults accepted longer delays for a larger reinforcer compared to young adults and children (Green, Fry, \& Myerson, 1994).

There is a theoretical basis for reductions in impulsivity in older adulthood. SocioEmotional Selectivity Theory (SST) states that as individuals get older, -social motives" shift from gaining knowledge to regulating emotions and emotional needs (Löckenhoff \& Carstensen, 2004). According to SST, older adults experience better control over their emotions, demonstrating a reduced focus on long-term goals and increased desire for interpersonal harmony. They evidence less impulsivity and perhaps fewer negative emotions overall (Löckenhoff \& Carstensen, 2004). As a consequence of an increased desire for day-to-day closeness, relationships take precedence, and disruption of these bonds may be particularly damaging. At its extreme, older adults may be more likely to feel like a burden and that they do not belong, potentially leading to the desire for suicide (Cukrowicz, Cheavens, Van Orden, Ragain, \& Cook, 2011). A focus on interpersonal harmony and needs in older adulthood may contribute to differences in motivations for suicidal behaviors between younger and older adults.

Clearly, developmental differences must be taken into account when studying any risk factor for suicidal behaviors. Conwell et al. (1998) found that older adults were less likely than younger adults to verbalize their intent to die by suicide. There were also differences in selfreported history of attempts between younger and older adults. However, the fact that a recent comprehensive review of the relation between impulsivity and suicide did not mention age differences points to neglect of these factors (Gvion \& Apter, 2011).

Studies that have examined age at death by suicide have found that impulsivity and related personality pathology is more common in young adults who died by suicide than older adults who died by suicide (e.g., Dumais et al., 2005). In other words, highly impulsive 
individuals who die by suicide are more likely to be young. In these studies, impulsivity was found to be associated with aggression and significant personality pathology, such as Borderline Personality Disorder, one of the Cluster B personality disorders (Gvion \& Apter, 2011).

Three studies of individuals who died by suicide have found similar relations between age, impulsivity, and related psychopathology. In each study, researchers conducted psychological autopsies, (chart reviews and interviews with family, friends, and health care providers), and some used a similar method to establish a matched control group. Zouk, Tousignant, Sequin, Lesage, \& Turecki (2006) examined Barratt Impulsiveness Scale -11 scores in a sample of consecutive suicide completers in a geographical region. Researchers divided the individuals who died by suicide into two groups based on BIS-11 scores (above the $70^{\text {th }}$ and below the $30^{\text {th }}$ percentile for scores on this measure). Although rates of depression were similar between the two groups, -impulsive suicide completers" were more likely to be young, abuse drugs and alcohol, exhibit Cluster B personality disorder symptoms, and have more psychiatric diagnoses.

Dumais et al. (2005) examined males of all ages who were depressed and died of suicide and compared them to depressed living men. There were more impulsive men, as measured by BIS-11, in the suicide group than in the non-suicide group. The relation between impulsiveaggressive behaviors and suicide was significant for men under 40 but not for those over 40 years of age. In both studies, drug and alcohol abuse, Cluster B personality disorders, and aggressive behavior were significantly associated with death by suicide and impulsivity. Impulsivity and aggression likely underlie Cluster B disorders, substance abuse, and substance dependence, which confer direct risk for suicidal behavior (Tcheremissino, Lane, Cherek, \& Pietras, 2003). 
Further supporting age differences in impulsivity among individuals who die by suicide, McGirr et al. (2007) studied 645 cases of death by suicide. Using age as a continuous variable, no relation was found between age and BIS-11 score among control group participants. However, among those who had died by suicide, age predicted BIS-11 score, with younger individuals reporting higher impulsivity.

Younger and older people who engage in overt suicidal behavior seem to differ in the psychopathology and personality they display. Upon reviewing the accumulated evidence, Gvion \& Apter (2011) concluded that individuals who engage in overt suicidal behaviors can be divided roughly into two categories: for some individuals, suicidal behavior is predicted by impulsivity and violence, whereas for others, these behaviors are primarily the functions of depression. Turecki (2005) noted that impulsivity is related to personality disorders and general comorbidity, the result of patterns begun early in life. Older adult suicide, compared to younger suicide, has been shown to be more related to depression, recurrent depressive episodes and dysthymia, physical illness, and to be the result of a planned act (Beautrais, 2002, McGirr et al., 2007). Additional unpublished data discussed by Turecki (2005) lead the author to conclude that impulsive-aggressive behaviors are more likely to be observed in younger suicide deaths rather than older suicide deaths.

Applying Joiner's (2005) theory to these findings, perhaps young adults who are predisposed to impulsivity acquire the capacity to harm themselves earlier in life. Thus, young adults' acquired capacity and suicidal behaviors are more contingent on high levels of impulsivity, while older adults have a lifetime to experience - painful and provocative" events. Older adults who desire suicide and die by suicide, spurred by changes in burdensomeness or belongingness, have slowly accumulated the capacity to harm themselves. Thus, deaths by 
suicide in older adulthood may be less related to impulsivity. Although this does not account for older adults who have high levels of impulsivity, past research suggests that the relation between impulsivity and suicide is weaker in older adulthood. This theoretical framework also does not account for suicidal ideation, which is independent from the capacity for self-harm. The current study seeks to distinguish risk factors related to suicidal ideation from those for death by suicide.

\section{Gender, impulsivity, and suicidal behavior}

Men comprise a significant majority of individuals who die by suicide. In 2009, the rate for death by suicide for men was 19.2 of 100,000, compared to 5.0 of 100,000 for women in all age groups (McIntosh, 2012). Older adult males have the highest rate of suicide of all groups, reaching 35.7 per 100,000 for men over 75 in 2008 (Alexopoulos, 2010). The studies described above that examined deaths by suicide include many more men than women. For example, of consecutive suicide deaths in a geographic area, $84 \%$ of the non-impulsive" and $90 \%$ of the impulsive" individuals included in Zouk et al. (2006) were male. Considering that women are more likely than men to report depressive symptoms, factors other than affective illness are clearly at work (Zunzunegui et al., 2007). Women are more likely to think about and attempt suicide (Straiton, Roen, \& Hjelmeland, 2012; Maser et al., 2002), but men are more likely to attempt suicide using highly lethal means and therefore are more likely to die (Conwell \& Brent, 1996). This phenomenon has been termed the gender paradox" (Canetto \& Sakinofsky, 1998; Schrijvers, Bollen, \& Sabbe, 2012). Although varying by culture and not typically linear (i.e., progressing from less serious to more severe suicidal behavior), women tend to have a longer suicidal process, including ideation and a series of non-fatal attempts (De Leo, Cerin, Spathonis, \& Burgis, 2005). Men's process tends to be shorter. Men may also be likely to make attempts with high lethality because surviving a suicide attempt is associated with greater stigma for men 
than women. (Canetto \& Sakinofsky, 1998; Schrijvers, Bollen, \& Sabbe, 2012). Because of these gender differences, men who die by suicide are less likely than women to have previously made a suicide attempt, increasing the difficulty of risk detection and prevention of an eventual suicide death (Conwell et al., 1998).

Factors that increase men's risk for death by other means, including accidents and healthrelated deaths, may also explain their increased rates of suicide. A large prospective study of male soldiers found that personality characteristics of those who died by suicide and those who died in accidents were surprisingly similar (Angst \& Clayton, 1998). These tendencies included high spontaneous aggression, depressive symptoms, excitability, and reactive aggression. This type of finding highlights how Joiner's theory accounts for high rates of suicide in men. Men are more likely than women to be exposed to painful and provocative events and acquire capability for self-harm (Joiner, 2005). This may occur through participating in combat, fights, and physically dangerous risk-taking that is more normative for men than women (Joiner, 2005). Impulsivity in men is also related to alcohol abuse, a key factor in many suicides (as well as deaths categorized as accidents) and a contributing factor in the gender paradox" (Canetto \& Sakinofsky, 1998). Overall, researchers have noted greater importance of studying male suicide in particular since it is much more prevalent (Angst \& Clayton, 1998; Joiner, 2011)

In a review of the literature on personality and suicidal behaviors, Brezo et al. (2004) concluded that certain personality traits may be differently clustered in suicidal men and women, with suicidal women being more introverted, negativistic, avoidant, dependent, borderline, and neurotic, and suicidal men being more impulsive, hostile, and antisocial. Confirming some of these conclusions, Oquendo et al. (2007) found that predictors for a future suicide attempt or death by suicide for young adults who had experienced major depression were very different for 
men and women, although the role of impulsivity was unclear and confounded by the presence of Borderline Personality Disorder. Baca-Garcia et al., (2005) found that impulsivity, as measured by the BIS-11, was significantly correlated with the impulsivity of a suicide attempt among men $(r=.22)$, but not women (correlation not reported). Cherek and colleagues found that impulsivity was elevated for both male and female violent parolees, however, the relation between impulsivity and aggression was significant for males, but not females (Cherek \& Lane, 1999; Cherek, Moeller, Dougherty, \& Rhoades, 1997). These studies suggest that impulsivity may be differently related to men's and women's suicidal and aggressive behavior.

A greater understanding of personality and other risk factors for suicidal behaviors in men could enhance prevention efforts, which currently are not very effective, especially for older men (Conwell, 2009). Masculine gender role traits and the conflicts caused by changing gender roles and expectations may lead men to engage in dangerous behaviors, aggression, anger, and alcohol abuse, all the while being unwilling to seek help (Joiner, 2011; Möller-Leimkühler, 2002). They may also not be identified by professionals as having a psychological problem, as Magovcevic and Addis (2008) and Price et al. (2011) found that men who reported a high level of adherence to traditional masculine gender roles were more likely to report externalizing symptoms such as aggression, drinking, and physical complaints, which may not be identified by traditional measures of depression or DSM-IV criteria.

\section{Statement of the problem}

Rates of suicidal behaviors vary over the lifespan, but little research has focused on developmental aspects of suicidal behaviors and associated risk factors (McIntosh, 2012). Previous studies suggest that young people who attempt or die by suicide are likely to be generally impulsive in many areas of their lives (e.g., McGirr 2007). The link between 
impulsivity and suicidal behavior, in the context of depression or other psychopathology, has been firmly established in younger adults. However, these variables have less frequently been explored in older adults, and the two groups have not been compared.

Most research has focused on suicide attempts and deaths, but the relation of impulsivity with suicidal ideation may also be relevant. Thinking about and planning for suicide - suicidal ideation - is a clear risk factor for suicide attempts and completions (e.g., Mann et al., 1999; Wyder \& De Leo, 2007). According to Joiner, an individual who mentally rehearses suicidal acts may acquire capability to harm themselves through that rehearsal (Joiner, 2005).

Impulsivity may contribute to the development of ideation because an impulsive individual, with more sensitivity to short-term consequences, will have a greater tendency to act rashly and escape uncomfortable emotional stimuli. He or she may more quickly envision suicide as a solution or use thoughts of suicide as a distraction from other thoughts or feelings. There is some evidence that suicidal ideation is related to impulsivity in both younger and older adults, but the research on this topic has been scant, with only one study that examined the issue in older adults (Neufeld \& O'Rourke, 2009). To my knowledge, there have been no direct comparisons of older and younger adults regarding impulsivity and suicidal ideation and attempts.

Specific Aim 1 was to examine the relation between impulsivity and suicidal ideation and past attempt in younger and older adults. Psychological autopsy studies have revealed that impulsive people who die by suicide tend to be younger than non-impulsive suicide completers (McGirr et al., 2007; Zouk et al., 2006). Based on these findings, the tendency to behave impulsively may function differently as a risk factor for suicidal behavior in younger and older adults. The hypothesis was that self-reported impulsivity, in the context of depressive symptoms, 
would be more highly related to self-reported suicidal ideation and attempts in younger adults than in older adults.

Specific Aim 2 was exploratory. I examined and compared the relation between impulsivity and suicidal ideation and attempts in younger and older adult men and women, in the context of depressive symptoms. Overall rates of suicidal behaviors (i.e., attempts and deaths by suicide) differ greatly based on gender. It is unclear whether impulsivity plays a role in those gender differences, especially in older adults.

\section{Method}

\section{Participants and Procedure}

The Mental Health and Aging Lab at West Virginia University collected the data used in this project from 2009 to 2011 . One hundred and eight community-dwelling older adults and 498 undergraduate students completed questionnaires. The questionnaires contained the measures used in this project and several others, totaling approximately 300 items.

Recruitment of young adult subjects ages 18 to 30 took place in undergraduate psychology classes at West Virginia University. Students were directed to an online research participation system. Any undergraduate student with access to the SONA system could also choose to participate. Young adults received extra credit in their class as an incentive to participate.

Recruitment of older adults over age 60 took place at senior centers, an assisted living facility, and health fairs. Individuals who appeared to be over the age of 60 were approached by researchers and asked once if they would like to participate in the study. Older adults completed the same items as younger adults, although in a paper format. If older adults were not able or did not choose to finish the survey when researchers were present, they were provided with a stamped envelope in which to return the survey. Older adults received five dollars at the time 
they agreed to participate in the study and signed a receipt for cash received, kept separately from the completed survey.

In order to protect confidentiality, the need for signed informed consent forms was waived for both younger and older adult participants. All participants read a cover letter that explained the nature of the project. It stated that participants gave their consent to participate by completing the survey. The only risk participants might have incurred was discomfort or upset related to the content of the questions. To mitigate this risk, every participant was provided with a list of local mental health resources, including low- or no-cost services. This procedure was approved by the Institutional Review Board at West Virginia University.

All data were examined carefully for careless or biased responding. This included very short completion times for the SONA study (less than 12 minutes), apparent inattention to reverse-scored items, and idiosyncratic patterns such as alternating between the first and second answer choices for the entire survey. In addition, five participants between the ages of 31 and 59 were excluded. After all invalid cases were removed, analyses were performed on the responses of 474 younger adults and 105 older adults.

$\mathrm{G}^{*}$ Power was used to conduct an a priori power analysis to determine if adequate power could be achieved with the current sample (Faul, Erdfelder, Lang, \& Buchner, 2007). A twotailed linear multiple regression model was entered with a total of seven predictors (age group or gender, depressive symptoms, impulsivity, three two-way interactions, , and the three-way interaction between depressive symptoms, impulsivity, and age group). Predicting a small to medium effect size of $f^{2}=.10$, the total sample size needed to achieve high (.80) power was calculated to be 81 . This effect size is estimated based on the effect size of the relation between impulsivity and suicidal ideation reported by Conner et al. (2004). The current sample size 
provided ample power for Aim 1 as well as allowed for the older and younger adult samples to be analyzed separately in Aim 2.

\section{Measures}

Suicidal ideation and attempts. The Suicidal Behaviors Questionnaire - Revised (SBQ$\mathrm{R})$ is a 4-item self-report measure that queries past and estimations of future suicide risk. The SBQ-R was based on a 36-item interview developed by Marsha Linehan and reduced to four items by Cole (1988). Cole conducted a factor analysis of the SBQ-R and found that the four items loaded onto one factor, which may be conceptualized as the individuals' current evaluation of their suicide risk. Most questions and answer choices reflect content related to suicidal ideation. Response choices are different for each question and the number of response choices ranges from four to six (see Appendix A for items). Total scale scores range from 3 to 20 , with greater scores indicating more risk.

Cotton, Peters, Range (1995) examined the SBQ-R and found a Cronbach's alpha of .80 in a non-clinical sample. In an adult clinical sample, reliability was also moderately high, .87 (Osman et al., 2001). Test-retest reliability after two weeks was very good $(r=.95)$. Convergent validity for the full scale was established with Beck's Scale for Suicidal Ideation $(r=.69)$ and the Reasons for Living Inventory ( $r=-.34$ ) (Cotton, Peters, \& Range, 1995). In the current study, standardized Cronbach's alphas for the full scale were good, .79 for older adults and .84 for younger adults.

An endorsement of any answer other than -never" on the first question on the SBQ-R, which asks about the frequency of suicidal ideation and attempts in the past year, was shown to differentiate between suicidal and non-suicidal groups with $100 \%$ sensitivity and $96 \%$ specificity (Osman et al., 2001). In this project, scores on the full SBQ-R were used as the outcome variable 
for most analyses. Additional analyses used the answer to item 1 to determine if the individual did or did not report a past suicide attempt. Individuals who endorsed the answers thave attempted to kill myself, but did not want to die" or Thave attempted to kill myself, and really hoped to die" (answers - d" and f') were coded as having a previous suicide attempt.

Impulsivity. The Barratt Impulsiveness Scale Version 11 (BIS-11) is a 30-item selfreport measure of impulsivity. The scale was first published in 1959 and has been continually updated (Barratt, 1965; Standford et al., 2009). Individuals respond on a Likert scale with four answer choices: rarely/never, occasionally, often, and almost always/always. Some of the items are reverse-scored (see Appendix B for items). It contains three factors: motor, non-planning, and attentional/cognitive impulsiveness (Patton, Stanford, \& Barratt, 1995; Standford et al., 2009). Previous research has found, for example, that alcoholics demonstrated cognitive, but not motor impulsivity, and that these constructs are distinct (Mitchell et al., 2005). Few researchers have published results based on hypotheses about these individual factors, however (Standford et al., 2009). Because the attentional/cognitive factor is hypothesized to be related to decisions and thinking, it was examined in relation to a measure tapping suicidal ideation (Patton et al., 1995).

The original BIS was found to be orthogonal to measures of both anxiety and emotional stability (Barratt, 1965). BIS-11 scores have been found to be elevated in many clinical groups, including substance users, individuals with conduct disorder and ADHD, bipolar disorder, and forensic populations. Providing additional construct validity, performance on behavioral delaydiscounting tasks has been found to correlate with self-report of impulsivity on the BIS (Cherek \& Lane, 1999; Mitchell et al., 2005).

Previous psychometric evaluations support the use of the BIS-11. Cronbach's alpha for the total BIS-11 has been found to be moderately high in previous studies, .83 (Stanford et al., 
2009). Test-retest reliability (Spearman's rho) for the full scale BIS-11was .83 and for the three factors ranged from .61 to .72 . The BIS-11 has shown convergent validity with the Zuckerman Sensation-Seeking Scale and the Eysenck Impulsiveness Scale (Stanford et al., 2009).

In the current study, internal reliability of the BIS-11 was good, standardized Cronbach's alpha of .82 for older adults and .84 for younger adults. The current study achieved an acceptable Cronbach's alpha of .73 for the attentional/cognitive subscale in younger adults. In older adults, internal consistency for the attention/cognitive subscale was fair, .65.

Depressive symptoms. The Center for Epidemiological Studies - Depression Scale (CES-D) is a 20-item self-report inventory of depressive symptoms. Participants indicate their experience of these symptoms in the past week on a 4-point scale from frarely or not at all" to most of the time." Developed as a screening tool, it has been widely used in clinical psychology research and practice. Radloff (1977) reported good internal consistency for the CES-D, ranging from a Cronbach's alpha of .85 to .90 . He determined that test-retest reliability was moderate over six months, $r=.54$ for those without negative life events in the interval between testing. Test-retest reliability decreased to .32 after 12 months. The CES-D has been validated in older adult samples (Gatz, Johansson, Pederson, Berg, \& Reynolds, 1993). Some researchers have noted that the CES-D is acceptable for use with older adults because scores are not overly impacted by physical illness (Gatz et al., 1993). See Appendix C for items.

For the current study, standardized Cronbach's alphas for the CES-D were good, .84 in older adults and .90 in younger adults.

Demographic questions. Relevant demographic questions included racial/ethnic group, age, gender, marital status, present work status, rurality of hometown, and educational level.

\section{Results}


All results were computed using SAS 9.2.

\section{Descriptive Statistics}

Descriptive statistics for demographic variables are displayed in Table 1 by age group and gender.

Differences by age group. Younger adults had a mean age of 20.01 (SD = 1.89); older adults had a mean age of $73.62(\mathrm{SD}=8.56)$. The two groups differed on several demographic variables. Marital status varied between the groups, with older adults overrepresented in the married/partnered" or -separated/divorced/widowed" categories; young adults were more likely to be single $\left(\chi^{2}=397.87, p<.001\right)$. There were differences in occupation: older adults were more likely to be not working (i.e., retired, disabled, or a homemaker). Although all young adult participants were enrolled in psychology courses at West Virginia University, some of these students identified themselves as primarily working part time" or working full time." However, the younger adults were more likely to report being primarily students $\left(\chi^{2}=489.11, p\right.$ $<.001)$. Education level for younger adults was uniformly undergraduate status by design. About half of older adults reported an education level above high school. Older adults were more likely to report attending church more than once per month $\left(\chi^{2}=28.98, p<.001\right)$. Despite their other differences, the two groups were similar on rurality of hometown $\left(\chi^{2}=2.83, p=.419\right)$.

Descriptive statistics for study variables by age group and gender are presented in Table 2. Older and younger adults demonstrated mean-level differences on the study measures. Younger adults reported significantly more depressive symptoms, $t(1,573)=4.06, p<.001, \mathrm{~d}=$ 0.44 , and higher impulsivity, $t(1,561)=6.72, p<.001, \mathrm{~d}=0.77$. Results were similar for the attentional/cognitive subscale of the BIS-11, $t(1,566)=7.85, \mathrm{p}<.001, \mathrm{~d}=0.88$. Younger adults 
also tended to score higher on the measure of suicidal behaviors, although with a smaller effect size compared to the other age differences, $t(1,567)=2.36, p=.019, \mathrm{~d}=0.26$.

Differences by gender. Within each age group, no gender differences in demographic variables were detected. Men and women did not significantly differ by occupation, educational attainment, marital status, attendance at church, or rurality according to Chi Square analyses.

An examination of mean-level differences on study measures for men and women revealed a similar pattern. T-tests revealed no significant differences in scores between men and women, within age group, on the CES-D, BIS-11, the BIS-11 attentional/cognitive subscale, or the SBQ-R.

\section{Missing Data and Assumptions for Linear Regression}

Missing data were imputed by participant and scale for the BIS-11, BIS-11 attentional/cognitive subscale, and the CES-D. If a participant had provided at least $80 \%$ of the responses for an individual scale, then his or her mean item score was imputed into the missing value. Cases were deleted for analyses that included a scale on which approximately $20 \%$ or more of the participant's responses were missing. Percentages were approximate because some scales contained a number of items that could not be divided by ten. In those cases, a conservative number was used such that participants needed to provide at least $80 \%$ of responses to be included.

Before testing hypotheses, the data were examined to determine if they fulfilled assumptions of linear regression. Scatter plots showed roughly linear relations between scores on all three self-report measures. The dependent variable, SBQ-R, was skewed and kurtotic because $52.9 \%$ of participants reported no suicidal behaviors, skew $=1.93$ and kurtosis $=3.48$. A square root transformation improved the skew and kurtosis of that variable, skew $=1.53$ and kurtosis $=$ 
1.56. The mean of the transformed $\mathrm{SBQ}-\mathrm{R}$ variable was $2.09, \mathrm{SD}=.51$. There appeared to be some heteroscedacity, with a large range of BIS-11 and CES-D scores represented at the smallest value of the SBQ-R. However, linear regression is a robust statistical procedure with regard to heteroscedacity (Howell, 2010).

Correlations between CES-D and SBQ-R scores were medium-sized (see Table 3). Correlations between the BIS-11, its subscale, and the CES-D and SBQ-R were small. The correlation between impulsivity and suicidal behaviors appeared to be stronger in older adults than in younger adults (see Table 4). Colinearity problems were not anticipated because the independent variables were not highly related.

\section{Hypothesis Testing}

CES-D and BIS-11 scores were centered by mean score across all participants to complete the following analyses, as suggested by Aiken and West (1991). The means used for centering are displayed in Table 3.

Aim 1: Impulsivity, Suicidal Behaviors, and Age Group. I hypothesized that selfreported impulsivity would be more highly related to self-reported suicidal ideation and attempts, in the context of depressive symptoms, in younger adults than in older adults. This was analyzed using a linear regression. The three-way interaction between age group, impulsivity, and depressive symptoms was used to predict the outcome of suicidal ideation and attempts (full

SBQ-R score). Variables included in the model were age group (younger or older), impulsivity (BIS-11), and depressive symptoms (CES-D). Aiken and West (1991) suggest that all two-way interaction should be controlled for when testing a three-way interaction. Thus, additional interaction terms of BIS-11 x CES-D, age group x BIS-11, and age group x CES-D were 
included in the model. Gender did not account for a significant amount of variance in the full SBQ-R score, and was not included in this or subsequent analyses.

Controlling for the main effects of age group, CES-D, BIS-11, and all two-way interactions, the three-way interaction between age group, CES-D, and BIS-11 was not significant, $\mathrm{b}^{*}=-.02, S E=.00, t(1,554)=.29, p=.771$. The overall $\mathrm{R}^{2}$ for the model was $.22, F$ $(7,55)=21.94, p<.001$. Most of the variance was accounted for by the CES-D, $R^{2}$ change $=.19$ when entered second in the model after age group. This pattern was seen in each subsequent analysis.

Next, a logistic regression was conducted to examine the effects of the independent variables on past suicide attempt (i.e., reporting a past attempt versus not reporting a past attempt), as measured by the first item of the SBQ-R. The three-way interaction between CES-D, BIS-11, and age group was not a significant predictor of attempt status, Wald Chi-Square $=2.80$, $p=.094(O R=.99,95 \% \mathrm{CI}: .98-1.00)$.

For a follow-up analysis, the dependent variable was trichotomized based on answers to the first item on the SBQ-R: 0 represented no report of suicide attempt, 1 represented a past suicide attempt with low intent (i.e., answered -attempted suicide but did not really want to die), and 2 represented a past attempt with high intent (i.e., answer -attempted suicide and really wanted to die"). The main effect of age group was a significant predictor of intent level/attempt status, Wald Chi-Square $=10.20, p=.001$. Older adults were more likely to report suicidal attempts with higher intent $(O R=8.46,95 \% \mathrm{CI}: 2.28-31.37)$. Controlling for all main effects and two-way interactions, the three-way interaction between CES-D, BIS-11, and age group to predict level of intent/attempt status was not significant, however, Wald Chi-Square $=370, p=$ $.054(O R=.99,95 \%$ CI: $.98-1.00)$. 
An additional exploratory analysis used the BIS-11 attentional/cognitive subscale as a predictor variable, in place of the full BIS-11.Controlling for all main effects and two-way interactions, the three-way interaction between CES-D, BIS-11 attentional/cognitive subscale, and age group did not account for a significant amount of the variance in SBQ-R scores, $b^{*}=$ $.06, S E=.00, t(1,558)=-1.03, p=.303$.

Aim 2: Impulsivity, Suicidality, and Gender. The relation between impulsivity and suicidal behavior in men and women was examined separately for younger and older adults using linear regressions. Variables entered into the model were gender, impulsivity (BIS-11), depressive symptoms (CES-D), and all two-way interactions. The three-way interaction between gender, impulsivity, and depressive symptoms was used to predict the outcome variable of suicidal ideation and past attempt (full SBQ-R). For younger adults, the three-way interaction was not significant, $b^{*}=-.01, S E=.00, t(1,469)=-.20, p=.842$. For older adults, the threeway interaction between impulsivity, depressive symptoms, and gender was also not significant, $b^{*}=.15, S E=.00, t(1,83)=0.77, p=.446$.

There appeared to be a significant main effect of impulsivity on suicidal behavior in older adults. Controlling for gender and depressive symptoms, impulsivity predicted suicidal behavior in older adults, $b^{*}=.12, S E=.004, t(1,83)=2.54, p=.013$. This finding was then examined separately for older adult women and men. Interestingly, for women, impulsivity was significantly associated with suicidal behavior, controlling for depressive symptoms, $b^{*}=.36$, $S E=.01, t(1,49)=2.77, p=.008$. For men, it did not, $b^{*}=.08, S E=.01, t(1,29)=0.56, p=$ .591 . However, when the two-way interaction between gender and impulsivity, controlling for depressive symptoms, was used to examine this gender difference, it was not statistically significant, $b^{*}=-.08, S E=.01, t(1,83)=-0.58, p=.563$. 


\section{Discussion}

The current study examined the relation between self-reported impulsivity and suicidal ideation and attempts. The predicted interaction between depressive symptoms, impulsivity, and age group was not significant in any regression and therefore the hypothesis of Aim 1 was not supported. Contrary to expectations, there was a main effect of impulsivity in older adults, but not younger adults, controlling for gender and depressive symptoms. Depressive symptoms accounted for an overwhelming portion of the variance in these analyses.

Aim 2 addressed gender differences in the relation between impulsivity and suicidal behaviors within each age group. Contrary to the accumulated research evidence and clinical wisdom, no significant relation between impulsivity and suicidal behaviors was found in younger adults or men of any age. Within each age group, there was no gender difference detected in the strength of the relation between impulsivity and suicidal behavior.

Considering a broad array of genetic, biological, and psychological factors, Joiner and colleagues identified -deregulated impulse control" as one of two main classes of risk factors for suicide (Joiner, Brown, Wingate, 2005). There are several reasons why this assertion may not have been supported as predicted in the present study. First, the bulk of the empirical literature focuses on suicide attempts and deaths by suicide as outcomes (Joiner, Brown, Wingate, 2005). Although the present study included an item that inquired about suicide attempts, only about 3\% of the participants in this study reported a past attempt. The current sample was very different from samples of individuals made up entirely of those who had previously attempted or died by suicide. For the present study, hypotheses were based on the existing evidence regarding a range of suicidal behaviors and impulsivity. The lack of available research on suicidal ideation and impulsivity necessitated this approach. The results of the current study highlight the finding that 
suicidal ideation is a distinctly different behavior from attempts and deaths, with different correlates and risk factors (Brezo et al., 2006).

Perhaps impulsivity as a risk factor is relevant for suicide attempts and deaths but not ideation. Impulsivity, according to Joiner's theory, may increase the number of painful and provocative events in one's life, and thus contribute to acquired capability, the ability to make a serious suicide attempt or die by suicide (Joiner, 2005; Witte et al., 2008). The link between impulsivity and suicidal ideation hinges on cognitive impulsivity and escape from aversive thoughts or feelings. Suicidal behavior is often considered to be a highly impulsive and rash behavior. A definition of impulsivity might be a choice for certain short-term consequences over other long-term future consequences. If so, taking steps to end one's life could be considered the ultimate impulsive act. However, suicidal thoughts and attempts as measured in the current study did not seem to follow this pattern. Although suicidal ideation might not be contingent upon painful and provocative acts or the capacity for suicide as other suicidal behavior, it could be conceptualized as part of the desire for suicide, the other main part of Joiner's theory.

As indicated above, studies that have found links between impulsivity and suicidal behaviors have most often used clinical samples. Pezawas et al. (2002) and Mann et al. (1999) found a relation between impulsivity and suicidal behaviors, including ideation, in individuals with depressive disorders. Although not necessarily diagnosed or seeking treatment for depression, self-reported depressive symptoms were over the CES-D clinical cut-off for many of the younger adult participants in the current study. Of young adult participants, $40.9 \%$ scored over the clinical cutoff of 16 on the CES-D (compared to $25.7 \%$ of older adult participants), yet impulsivity was not an independent predictor in the young adult sample (Radloff, 1977). Even though the CES-D measured depressive symptoms in the past week, it made up much more of 
the variance in suicidal behaviors, compared to impulsivity. This effect was demonstrated in spite of the fact that impulsivity and suicidal behaviors were a better -match" because they were measured by assessments that probed lifetime and global risk. Still, it is likely that even high levels of self-reported depressive symptoms are not equivalent to a diagnosis of depressive disorder and that participants in this study had different qualities than clinical samples.

Two interesting findings emerged in the older adult sample. Exploratory analyses revealed that impulsivity predicted suicidal behaviors in older women, above and beyond depressive symptoms. This was not found to be true for older men, although the gender different was not significant. The tendency for women to experience more suicidal ideation and attempts (even if these are not reflected in a self-report survey) may have contributed to the significant effect found in older women (Schrijers, Bollen, \& Sabbe, 2011). Perhaps this relation was not detected in men due to the lack of statistical power resulting from the smaller number of older adult men included in the sample, especially after invalid cases were removed.

Additionally, a logistic regression showed that age group significantly predicted the level of intent of past suicide attempts. Of those who reported a past suicide attempt, $83.3 \%$ of older adults had a strong intent to die, compared to $40 \%$ of younger adults. A prospective, casecontrolled study found that presence of past suicide attempts with high intent and high lethality was the most robust predictor of whether or not patients died by suicide (Coryell et al., 2002). Dombrovski et al. (2011) found that older adults who made highly lethal attempts were actually less impulsive than control groups and older adults who made low-lethality attempts. Suicidal ideation and plans for suicide in older adults should be taken very seriously, as these individuals seem to have a greater tendency than younger adults to carefully plan and carry out lethal suicidal behavior. 


\section{Limitations}

The current study used a cross-sectional design. A cross-sectional examination of two distinct age groups does not allow for conclusions about changes over the lifespan. However, these results may be useful concerning the current cohorts of older and younger adults.

The use of self-report measures of suicidal behaviors, impulsivity, and depressive symptoms may also be seen as a limitation of the current study. Participants may have provided certain responses for a variety of reasons (e.g., to please the experimenter, downplay, or exaggerate current problems). Encouraging for this type of research, though, studies of suicidal behavior in clinical populations have shown that subjective, self-report measures of depression or potential for suicide actually predicted suicidal behavior better than objective assessments completed by a professional (Joiner, Radd, \& Rajab, 1999; Mann et al., 1999; Oquendo, et al., 2004). Self-reports of impulsivity have also been shown to correlate with objective behavioral tasks measuring impulsivity (Cherek \& Lane, 1999; Mitchell et al., 2005).

Suicidal ideation is a difficult outcome to study because it is necessarily self-reported. The use of a non-clinical sample and a brief, general measure of suicide risk may be limitations of this study. Other studies that found the hypothesized relations used higher thresholds for suicidal ideation, such as the necessity for an increase in level of psychiatric care (Clark et al., 2011; Dombrovski et al., 2011). Those individuals are likely to be distressed or psychiatrically ill and thus have different characteristics than the participants in the current study. Perhaps impulsivity played a greater role in the behaviors defined as -suicidal ideation" in those studies. Other studies that have examined suicidal ideation used different assessments such as the Beck Suicide Ideation Scale (e.g., Neufeld \& O’Rourke, 2009), which may have resulted in different outcomes because it asks about current suicidal ideation and is sensitive to recent changes. 
However, the SBQ-R asks about past behaviors and estimations of future risk, so one might think it would be more stable and thus correlate better with a measure of an enduring predisposition such as impulsivity. Moreover, the SBQ- $\mathrm{R}$ is a validated measure and has been used in rigorous studies of suicide risk (e.g., Bryan, Clemans, \& Hernandez, 2012).

There is also a possibility that the measure of impulsivity used in this study was not optimal. A measure that focused on maladaptive behaviors used to reduce negative affect, such as the negative urgency subscale of the UPPS Impulsive Behavior Scale used by Anestis \& Joiner (2011), may have been a better match to predict suicidal behavior as conceptualized in this study. Whiteside et al. (2005) argued that impulsive acts might appear topographically similar but have an array of etiologies or goals (i.e., sensation-seeking or not considering the consequences versus trying to regulate difficult emotional states). This model of impulsivity seeks to clarify its multifaceted nature. For example, a recent study found that the sensationseeking subscale of the UPPS was most predictive of the capacity for suicide (Bender, Gordon, Bresin, \& Joiner, 2011). Similarly, a measure of impulsive-aggression, as used by Conner et al. (2003), might have been a better match to the type of impulsivity thought to contribute to suicidal behaviors. Compared to these other measures, the items on the BIS-11 are relatively benign (i.e., impulsivity is indicated by an inability to sit still) and neutrally valenced. Still, the BIS-11 has been shown to be related to a wide variety of serious psychological and behavioral problems including Bipolar Disorder, Conduct Disorder, and Borderline Personality Disorder (Standford et al., 2009).

Older adults and younger adults completed the surveys in different formats (online vs. paper-and-pencil), were approached for participation in a different manner, and received different types of compensation. However, both groups completed identical batteries. The higher 
mean levels of depressive symptoms, impulsivity, and suicidal behaviors among younger adults could be attributed to the more anonymous method of data collection. However, this should not have had an effect on the correlation between measures, within age group. The samples also varied by education level, marital status, and occupational status, variables that have been shown to influence suicidal behaviors (de Catanzaro, 1995, Joiner et al., 2005). However, both groups lived in the same geographical location at the time of data collection, were living in the community, and were willing and able to participate in psychological research. The differences in demographic characteristics were expected based on the age groups sampled. Younger and older adults did not differ by rurality, a variable also thought to influence suicidal behaviors (Hirsh, 2006). They also did not differ by race, another demographic variable that shows strong effects on rates of suicidal behaviors (AAS, 2012). The effect of administration and demographic differences might have been that older and younger adults would appear more different than could be attributed to their age (i.e., that the difference was attributable to their marital or occupational status, in addition to or despite of their age). However, there is little danger of this because the hypothesized age group differences were not detected.

This study had several strengths, including the use of an older adult sample. The average age of older adult participants was about 73 , indicating that this was a sample typically not captured in studies of adults. The use of two samples allowed for comparisons to be made on the impact of a risk factor that is usually discussed to be ubiquitous (impulsivity and its effect on suicide risk). This study included a careful characterization of the similarities and differences between the two samples. In addition, this study distinguished between types of suicidal behavior, especially suicidal ideation. The measures chosen were brief and easy to understand. 
The procedure allowed for anonymity in responding, which was designed to foster honest responding about difficult topics.

\section{Conclusions and Future Directions}

The long-term goal of this line of research is to better predict and intervene before individuals attempt or die by suicide. The current study examined an enduring predisposition, the tendency to act impulsively, which might have contributed differently to suicidal behavior in younger and older adults. The results raise more questions about the relatively well-established relation between impulsivity and suicidal behaviors. Future research should focus on integrating this risk factor into existing theories to explain why individuals engage in suicidal behaviors. Specifically, the tendency to commit impulsive acts may be a mechanism by which individuals acquire capability for self-harm over a lifetime. Joiner's (2005) theory provides an explanation for how impulsivity and suicidal behaviors may be related - the accumulation of painful and provocative events leading to higher acquired capability and lowered pain tolerance. Previous research has found that painful and provocative events mediate the relation between impulsivity and acquired capability for suicide attempts in both college student and outpatient clinical samples (Bender et al., 2011). Future research concerning impulsivity and suicidal behaviors should include measures of painful and provocative events and the capacity for suicide. Although impulsivity was not shown to be directly related to suicidal behaviors in this current study, it may be still be related to suicide attempts and deaths, perhaps indirectly.

Turecki (2005) and Bender et al. (2011) noted that impulsive patterns of behavior begin early in life but, as a consequence, are available for early and effective intervention. The current study did not provide evidence to suggest that impulsivity contributed to suicidal behavior in younger adults. However, the potentially mediating variables of painful and provocative events 
and capability for self-harm were not examined. Interventions and training for highly impulsive individuals are available and may be most useful for younger adults to mitigate the acquisition of capacity to inflict self-harm (Cherek et al., 2002; Möller et al., 2001). It is worth noting that all of the individuals in a study by Butler and colleagues (2010), men who had committed at least one violent criminal act, chose to remain on an SSRI that provided them with reductions in aggression and impulsivity after the study had ended. In other words, individuals who are highly impulsive may experience distress or problems and be amenable to reducing their impulsiveness.

The results of the current study confirm past findings that suggest that older adults may make suicide attempts with greater lethality or intent (Conwell et al., 2008). In addition, impulsivity and suicidal behavior were related in older women, contrary to expectations. Future studies should continue to explore personality and behavioral factors associated with suicidal behaviors in older adult men, who have very high rates of death by suicide. It is important to understand the ways in which existing suicide research does and does not apply to older adults, as well as men and women, so that clinicians may make accurate assessments of risk (Alexopoulos, 2010). Understanding when suicidal ideation is more likely to take place could allow earlier intervention or appropriate precautions. Suicidal ideation may be an indicator of a treatable psychiatric condition and a target deserving of treatment and research in itself. Cognitive-behavioral interventions for mood disorders are effective for older adults, but are underutilized (Fiske et al., 2009). Interventions for older adults in primary care have been shown to reduce suicidal ideation, although the ultimate impact on completed suicides is yet to be found (Conwell, 2009). Designing interventions that are effective and used by older men is a particular challenge for future clinicians and researchers (Möller-Leimkühler, 2002). 


\section{References}

Aiken, L. S. \& West, S. G. (1991). Multiple regression: Testing and interpreting interactions. Newbury Park, CA: SAGE Publications.

Alexopoulos, G.S., (2010). Dr. Alexopoulos replies. American Journal of Psychiatry, 167, 103103. doi: 10.1176/appi.ajp.2009.09091254r

American Association of Suicidology. (2012). Fact sheets: Reliable information about suicide... Retrieved from http:/www.suicidology.org/stats-and-tools/suicide-fact-sheets American Psychiatric Association. (2000). Diagnostic and statistical manual of mental disorders (4th ed., text rev.). Washington, DC: Author.

Anestis, M. D., \& Joiner, T. E. (2011). Examining the role of emotion in suicidality: Negative urgency as an amplifier of the relationship between components of the interpersonalpsychological theory of suicidal behavior and lifetime number of suicide attempts. Journal of Affective Disorders, 129(1-3), 261-269. doi:10.1016/j.jad.2010.08.006

Angst, J., \& Clayton, P. J. (1998). Personality, smoking and suicide: A prospective study. Journal of Affective Disorders, 51(1), 55-62. doi:10.1016/S0165-0327(98)00156-6 American Psychiatric Association. (2000). Diagnostic and statistical manual of mental disorders (4th ed., text rev.). Washington, DC: Author.

Baca-Garcia, E., Diaz-Sastre, C., Resa, E. G., Blasco, H., Conesa, D. B., Oquendo, M. A....de Leon, J. (2005). Suicide attempts and impulsivity. European Archives of Psychiatry and Clinical Neuroscience, 255(2), 152-156. doi:10.1007/s00406-004-0549-3

Barratt, E. S. (1965). Factor analysis of some psychometric measures of impulsiveness and anxiety. Psychological Reports, 16(2), 547-554.

Beautrais, A. L. (2002). A case control study of suicide and attempted suicide in older adults. 
Suicide and Life-Threatening Behavior, 32(1), 1-9. doi:10.1521/suli.32.1.1.22184

Bender, T. W., Gordon, K. H., Bresin, K., \& Joiner, T. E., Jr. (2011). Impulsivity and suicidality: The mediating role of painful and provocative experiences. Journal of Affective Disorders, 129(1-3), 301-307. doi:10.1016/j.jad.2010.07.023

Bryan, C. J., Clemans, T. A., \& Hernandez, A. M. (2012). Perceived burdensomeness, fearlessness of death, and suicidality among deployed military personnel. Personality and Individual Differences, 52(3), 374-379. doi:10.1016/j.paid.2011.10.045

Brezo, J., Paris, J., \& Turecki, G. (2006). Personality traits as correlates of suicidal ideation, suicide attempts, and suicide completions: A systematic review. Acta Psychiatrica Scandinavica, 113(3), 180-206. doi:10.1111/j.1600-0447.2005.00702.x

Bogner, H. R., de Vries, H. F., Maulik, P. K., \& Unützer, J. (2009). Mental health services use: Baltimore epidemiologic catchment area follow-up. The American Journal of Geriatric Psychiatry, 17(8), 706-715. doi:10.1097/JGP.0b013e3181aad5c5

Butler, T., Schofield, P. W., Greenberg, D., Allnutt, S. H., Indig, D., Carr, V.,...Ellis, A. (2010). Reducing impulsivity in repeat violent offenders: An open label trial of a selective serotonin reuptake inhibitor. Australian and New Zealand Journal of Psychiatry, 44(12), 1137-1143. doi:10.3109/00048674.2010.525216

Canetto, S. S., \& Sakinofsky, I. (1998). The gender paradox in suicide. Suicide and LifeThreatening Behavior, 28(1), 1-23.

Carli, V., Jovanović, N., Podlešek, A., Roy, A., Rihmer, Z., Maggi, S.,...Sarchiapone, M. (2010). The role of impulsivity in self-mutilators, suicide ideators and suicide attempters - A study of 1265 male incarcerated individuals. Journal of Affective Disorders, 123(1-3), 116-122. doi:10.1016/j.jad.2010.02.119 
Cherek, D., Lane, S., Pietras, C., \& Steinberg, J. (2002). Effects of chronic paroxetine administration on measures of aggressive and impulsive responses of adult males with a history of conduct disorder. Psychopharmacology, 159(3), 266-274. doi:10.1007/s002130100915

Cherek, D. R., \& Lane, S. D. (1999). Laboratory and psychometric measurements of impulsivity among violent and nonviolent female parolees. Biological Psychiatry, 46(2), 273-280. doi:10.1016/S0006-3223(98)00309-6

Cherek, D. R., \& Lane, S. D. (2000). Fenfluramine effects on impulsivity in a sample of adults with and without history of conduct disorder. Psychopharmacology, 152(2), 149-156. doi: $10.1007 / \mathrm{s} 002130000530$

Cherek, D. R., Moeller, F. G., Dougherty, D. M., \& Rhoades, H. (1997). Studies of violent and nonviolent male parolees: II. laboratory and psychometric measurements of impulsivity. Biological Psychiatry, 41(5), 523-529. doi:10.1016/S0006-3223(96)00426-X

Clark, L., Dombrovski, A. Y., Siegle, G. J., Butters, M. A., Shollenberger, C. L., Sahakian, B. J., et al. (2011). Impairment in risk-sensitive decision-making in older suicide attempters with depression. Psychology and Aging, 26(2), 321-330. doi:10.1037/a0021646

Cole, D. A. (1988). Hopelessness, social desirability, depression, and parasuicide in two college student samples. Journal of Consulting and Clinical Psychology, 56(1), 131-136. doi:10.1037/0022-006X.56.1.131

Conner, K. R., Conwell, Y., Duberstein, P. R., \& Eberly, S. (2004). Aggression in suicide among adults age 50 and over. The American Journal of Geriatric Psychiatry, 12(1), 37-42. doi:10.1176/appi.ajgp.12.1.37 
Conner, K. R., Duberstein, P. R., Conwell, Y., \& Caine, E. D. (2003). Reactive aggression and suicide: Theory and evidence. Aggression and Violent Behavior, 8(4), 413-432. doi:10.1016/S1359-1789(02)00067-8

Conner, K. R., Meldrum, S., Wieczorek, W. F., Duberstein, P. R., \& Welte, J. W. (2004). The association of irritability and impulsivity with suicidal ideation among 15 - to 20 -year-old males. Suicide and Life-Threatening Behavior, 34(4), 363-373.

doi:10.1521/suli.34.4.363.53745

Conwell, Y. (2009). Suicide prevention in later life: A glass half full, or half empty? The American Journal of Psychiatry, 166(8), 845-848. doi:10.1176/appi.ajp.2009.09060780

Conwell, Y., Duberstein, P. R., Cox, C., Herrmann, J., Forbes, N., \& Caine, E. D. (1998). Age differences in behaviors leading to completed suicide. The American Journal of Geriatric Psychiatry, 6(2), 122-126.

Conwell, Y., \& Brent, D. (1996). Suicide and aging I: Patterns of psychiatric diagnosis. In J. L. Pearson, Y. Conwell, J. L. Pearson \& Y. Conwell (Eds.), Suicide and aging: International perspectives. (pp. 15-30). New York, NY US: Springer Publishing Co.

Coryell, W., Haley, J., Endicott, J., Solomon, D., Leon, A. C., Keller, M., et al. (2002). The prospectively observed course of illness among depressed patients who commit suicide. Acta Psychiatrica Scandinavica, 105(3), 218-223. doi:10.1034/j.1600-0447.2002.10127.x

Cotton, C. R., Peters, D. K., \& Range, L. M. (1995). Psychometric properties of the suicidal behaviors questionnaire. Death Studies, 19(4), 391-397.

doi: $10.1080 / 07481189508252740$ 
Cukrowicz, K. C., Cheavens, J. S., Van Orden, K. A., Ragain, R. M., \& Cook, R. L. (2011). Perceived burdensomeness and suicide ideation in older adults. Psychology and Aging, 26(2), 331-338. doi:10.1037/a0021836

Dear, G. E. (2000). Functional and dysfunctional impulsivity, depression, and suicidal ideation in a prison population. Journal of Psychology: Interdisciplinary and Applied, 134(1), 77-80. doi: $10.1080 / 00223980009600850$

de Catanzaro, D. (1995). Reproductive status, family interactions, and suicidal ideation: Surveys of the general public and high-risk groups. Ethology and Sociobiology, 16(5), 385-394. doi:10.1016/0162-3095(95)00055-0

De Leo, D., Cerin, E., Spathonis, K., \& Burgis, S. (2005). Lifetime risk of suicide ideation and attempts in an australian community: Prevalence, suicidal process, and help-seeking behaviour. Journal of Affective Disorders, 86(2-3), 215-224. doi:10.1016/j.jad.2005.02.001

Dombrovski, A. Y., Szanto, K., Siegle, G. J., Wallace, M. L., Forman, S. D., Sahakian, B.,...Clark, L. (2011). Lethal forethought: Delayed reward discounting differentiates high- and low-lethality suicide attempts in old age. Biological Psychiatry, 70(2), 138144. doi:10.1016/j.biopsych.2010.12.025

Dumais, A., Lesage, A. D., Alda, M., Rouleau, G., Dumont, M., Chawky, N.,...Turecki, G. (2005). Risk factors for suicide completion in major depression: A case-control study of impulsive and aggressive behaviors in men. The American Journal of Psychiatry, 162(11), 2116-2124. doi:10.1176/appi.ajp.162.11.2116

Eysenck, H. J. (1993). The nature of impulsivity. In W. G. McCown, J. L. Johnson, M. B. Shure, W. G. McCown, J. L. Johnson \& M. B. Shure (Eds.), The impulsive client: Theory, 
research, and treatment. (pp. 57-69). Washington, DC US: American Psychological Association. doi:10.1037/10500-004

Eysenck, S. B., \& Eysenck, H. J. (1977). The place of impulsiveness in a dimensional system of personality description. British Journal of Social \& Clinical Psychology, 16(1), 57-68.

Faul, F., Erdfelder, E., Lang, A.-G., \& Buchner, A. (2007). G*Power 3: A flexible statistical power analysis program for the social, behavioral, and biomedical sciences. Behavior Research Methods, 39, 175-191.

Fiske, A., Wetherell, J. L., \& Gatz, M. (2009). Depression in older adults. Annual Review of Clinical Psychology, 5, 363-389. doi:10.1146/annurev.clinpsy.032408.153621

Garcia-Forero, C., Gallardo-Pujol, D., Maydeu-Olivares, A., \& Andres-Pueyo, A. (2009). Disentangling impulsiveness, aggressiveness and impulsive aggression: An empirical approach using self-report measures RID B-4719-2008 RID B-5178-2010. Psychiatry Research, 168(1), 40-49. doi:10.1016/j.psychres.2008.04.002

Gatz, M., Johansson, B., Pedersen, N., \& Berg, S. (1993). A cross-national self-report measure of depressive symptomatology. International Psychogeriatrics, 5(2), 147-156. doi:10.1017/S1041610293001486

Giegling, I., Olgiati, P., Hartmann, A. M., Calati, R., Möller, H., Rujescu, D.,... Serretti, A. (2009). Personality and attempted suicide. analysis of anger, aggression and impulsivity. Journal of Psychiatric Research, 43(16), 1262-1271. doi:10.1016/j.jpsychires.2009.04.013

Green, L., Fry, A. F., \& Myerson, J. (1994). Discounting of delayed rewards: A life-span comparison. Psychological Science, 5(1), 33-36. doi:10.1111/j.14679280.1994.tb00610.x 
Gvion, Y., \& Apter, A. (2011). Aggression, impulsivity, and suicide behavior: A review of the literature. Archives of Suicide Research, 15(2), 93-112. doi:10.1080/13811118.2011.565265

Hirsch, J. K. (2006). A review of the literature on rural suicide: Risk and protective factors, incidence, and prevention. Crisis: The Journal of Crisis Intervention and Suicide Prevention, 27(4), 189-199. doi:10.1027/0227-5910.27.4.189

Howell, D. C. (2010). Statistical methods for psychology. $7^{\text {th }}$ Ed. Belmont, CA: Cengage Wadsworth.

Joiner, T. (2005). Why people die by suicide. Cambridge, MA: Harvard University Press.

Joiner, T. (2011). Lonely at the top: The high cost of men's success. New York: NY: Palgrave Macmillan.

Joiner, T. E., Jr., Brown, J. S., \& Wingate, L. R. (2005). The psychology and neurobiology of suicidal behavior. Annual Review of Psychology, 56, 287-314. doi:10.1146/annurev.psych.56.091103.070320

Joiner, T. E. J., Rudd, M. D., \& Rajab, M. H. (1999). Agreement between self- and clinicianrated suicidal symptoms in a clinical sample of young adults: Explaining discrepancies. Journal of Consulting and Clinical Psychology, 67(2), 171-176. doi:10.1037/0022006X.67.2.171

Löckenhoff, C. E., \& Carstensen, L. L. (2004). Socioemotional selectivity theory, aging, and health: The increasingly delicate balance between regulating emotions and making tough choices. Journal of Personality, 72(6), 1395-1424. doi:10.1111/j.14676494.2004.00301.x 
Magovcevic, M., \& Addis, M. E. (2008). The masculine depression scale: Development and psychometric evaluation. Psychology of Men \& Masculinity, 9(3), 117-132. doi:10.1037/1524-9220.9.3.117

Mann, J. J., Waternaux, C., Haas, G. L., \& Malone, K. M. (1999). Toward a clinical model of suicidal behavior in psychiatric patients. The American Journal of Psychiatry, 156(2), 181-189.

Maser, J. D., Akiskal, H. S., Schettler, P., Scheftner, W., Mueller, T., Endicott, J.,...Clayton, P. (2002). Can temperament identify affectively ill patients who engage in lethal or nearlethal suicidal behavior? A 14-year prospective study. Suicide and Life-Threatening Behavior, 32(1), 10-32. doi:10.1521/suli.32.1.10.22183

McGirr, A., Paris, J., Lesage, A., Renaud, J., \& Turecki, G. (2007). Risk factors for suicide completion in borderline personality disorder: A case-control study of cluster B comorbidity and impulsive aggression. Journal of Clinical Psychiatry, 68(5), 721-729. doi:10.4088/JCP.v68n0509

McIntosh, J. L. (for the American Association of Suicidology). (2012). U.S.A. suicide: 2009 official final data. Washington, DC: American Association of Suicidology, dated January 12, 2012, downloaded from http://www.suicidology.org.

Mitchell, J., Fields, H., D'Esposito, M., \& Boettiger, C. (2005). Impulsive responding in alcoholics. Alcoholism-Clinical and Experimental Research, 29(12), 2158-2169. doi:10.1097/01.alc.0000191755.63639.4a

Möller, F., Barratt, E., Dougherty, D., Schmitz, J., \& Swann, A. (2001). Psychiatric aspects of impulsivity. American Journal of Psychiatry, 158(11), 1783-1793. doi:10.1176/appi.ajp.158.11.1783 
Möller-Leimkühler, A. M. (2002). Barriers to help-seeking by men: A review of sociocultural and clinical literature with particular reference to depression. Journal of Affective Disorders, 71(1-3), 1-9. doi:10.1016/S0165-0327(01)00379-2

Neufeld, E., \& O’Rourke, N. (2009). Impulsivity and hopelessness as predictors of suiciderelated ideation among older adults. The Canadian Journal of Psychiatry / La Revue Canadienne De Psychiatrie, 54(10), 684-692.

Odum, A. L. (2011). Delay discounting: Trait variable? Behavioural Processes, 87(1), 1-9. doi:10.1016/j.beproc.2011.02.007

Osman, A., Bagge, C. L., Gutierrez, P. M., Konick, L. C., Kopper, B. A., Barrios, F. X. (2001). The suicidal behaviors questionnaire - revised (SBQ-R): Validation with clinical and nonclinical samples. Psychological Assessment, 8(4), 443-454.

Oquendo, M. A., Bongiovi-Garcia, M. E., Galfalvy, H., Goldberg, P. H., Grunebaum, M. F., Burke, A. K.,...Mann, J.J. (2007). Sex differences in clinical predictors of suicidal acts after major depression: A prospective study. American Journal of Psychiatry, 164(1), 134-141. doi:10.1176/appi.ajp.164.1.134

Oquendo, M. A., Galfalvy, H., Russo, S., Ellis, S. P., Grunebaum, M. F., Burke, A.,...Mann, J.J. (2004). Prospective study of clinical predictors of suicidal acts after a major depressive episode in patients with major depressive disorder or bipolar disorder. The American Journal of Psychiatry, 161(8), 1433-1441. doi:10.1176/appi.ajp.161.8.1433

Patton, J. H., Stanford, M. S., \& Barratt, E. S. (1995). Factor structure of the barratt impulsiveness scale. Journal of Clinical Psychology, 51(6), 768-774. 
Pezawas, L., Stamenkovic, M., Jagsch, R., Ackerl, S., Putz, C., Stelzer, B.,...Kasper, S. (2002). A longitudinal view of triggers and thresholds of suicidal behavior in depression. Journal of Clinical Psychiatry, 63(10), 866-873. Retrieved from http://search.ebscohost.com/login.aspx?direct=true \&db=psyh\&AN=2002-08005$004 \&$ site $=$ ehost-live

Price, E. C., Gregg, J .J., Smith, M., Prentice, P., Fallen, T., Nazem, S., Nadorff, M. R., \& Fiske, (2011, November). Masculine depression scale detects additional symptoms in older men who endorse high masculinity. Poster presented at the Gerontological Society of American Annual Meeting: Boston, MA.

Radloff, L. S. (1977). The CES-D scale: A self-report depression scale for research in the general population. Applied Psychological Measurement, 1(3), 385-401. doi:10.1177/014662167700100306

Schrijvers, D. L., Bollen, J., \& Sabbe, B. G. C. (2012). The gender paradox in suicidal behavior and its impact on the suicidal process. Journal of Affective Disorders, 138(1-2), 19-26. doi:10.1016/j.jad.2011.03.050

Shneidman, E. S. (2004). Autopsy of a suicidal mind. New York, NY US: Oxford University Press.

Stanford, M. S., Mathias, C. W., Dougherty, D. M., Lake, S. L., Anderson, N. E., \& Patton, J. H. (2009). Fifty years of the barratt impulsiveness scale: An update and review. Personality and Individual Differences, 47(5), 385-395. doi:10.1016/j.paid.2009.04.008

Straiton, M. L., Roen, K., \& Hjelmeland, H. (2012). Gender roles, suicidal ideation, and selfharming in young adults. Archives of Suicide Research, 16(1), 29-43. doi:10.1080/13811118.2012.640613 
Swann, A. C., Dougherty, D. M., Pazzaglia, P. J., Pham, M., Steinberg, J. L., \& Moeller, F. G. (2005). Increased impulsivity associated with severity of suicide attempt history in patients with bipolar disorder. The American Journal of Psychiatry, 162(9), 1680-1687. doi:10.1176/appi.ajp.162.9.1680

Tcheremissine, O. V., Lane, S. D., Cherek, D. R., \& Pietras, C. J. (2003). Impulsiveness and other personality dimensions in substance use disorders and conduct disorders. Addictive Disorders \& their Treatment, 2(1), 1-7. doi:10.1097/00132576-200302010-00001

Tice, D. M., Bratslavsky, E., \& Baumeister, R. F. (2001). Emotional distress regulation takes precedence over impulse control: If you feel bad, do it! Journal of Personality and Social Psychology, 80(1), 53-67. doi:10.1037/0022-3514.80.1.53

Turecki, G. (2005). Dissecting the suicide phenotype: The role of impulsive-aggressive behaviours. Journal of Psychiatry \& Neuroscience, 30(6), 398-408.

Whiteside, S. P., Lynam, D. R., Miller, J. D., \& Reynolds, S. K. (2005). Validation of the UPPS impulsive behavior scale: A four-factor model of impulsivity. European Journal of Personality, 19(7), 559-574. doi:10.1002/per.556

Willems, S., Van der Linden, M., \& Marczewski, P. (2003). Sensation-seeking and impulsivity in young and older adults' decision making. Brain and Cognition, 51(2), 237-239.

Witte, T. K., Merrill, K. A., Stellrecht, N. E., Bemert, R. A., Hollar, D. L., Schatschneider, C.,...Joiner, T. E. (2008). "Impulsive" youth suicide attempters are not necessarily all that impulsive. Journal of Affective Disorders, 107(1-3), 107-116. doi:10.1016/j.jad.2007.08.010 
Wyder, M., \& De Leo, D. (2007). Behind impulsive suicide attempts: Indications from a community study. Journal of Affective Disorders, 104(1-3), 167-173. doi:10.1016/j.jad.2007.02.015

Zouk, H., Tousignant, M., Seguin, M., Lesage, A., \& Turecki, G. (2006). Characterization of impulsivity in suicide completers: Clinical, behavioral and psychosocial dimensions. Journal of Affective Disorders, 92(2-3), 195-204. doi:10.1016/j.jad.2006.01.016

Zunzunegui, M. V., Minicuci, N., Blumstein, T., Noale, M., Deeg, D., Jylhä, M.,...Pedersen, N. L. (2007). Gender differences in depressive symptoms among older adults: A crossnational comparison: The CLESA project. Social Psychiatry and Psychiatric Epidemiology, 42(3), 198-207. doi:10.1007/s00127-007-0158-3 
Table 1

\section{Participant Characteristics}

\begin{tabular}{|c|c|c|c|c|c|c|}
\hline \multirow[b]{2}{*}{ Variable } & \multicolumn{3}{|c|}{ Younger Adults } & \multicolumn{3}{|c|}{ Older Adults } \\
\hline & Total & Men & Women & Total & Men & Women \\
\hline$N$ & 474 & 118 & 356 & 105 & 36 & 67 \\
\hline Mean Age (SD) & $20.01(1.89)$ & $20.71(2.39)$ & $19.78(1.63)$ & $73.62(8.56)$ & $72.69(7.12)$ & $74.12(8.99)$ \\
\hline Caucasian (\%) & 91.14 & 88.98 & 91.85 & 93.07 & 91.43 & 93.94 \\
\hline Female $(\%)$ & 75.11 & & & 65.05 & & \\
\hline \multicolumn{7}{|l|}{ Years of Ed. (\%) } \\
\hline$\leq$ High School & $-^{\mathrm{a}}$ & - & - & 42.00 & 28.13 & 46.97 \\
\hline$>$ High School & - & - & - & 49.00 & 62.50 & 43.94 \\
\hline Other & - & - & - & 9.00 & 9.38 & 9.09 \\
\hline \multicolumn{7}{|l|}{ Marital Status (\%) } \\
\hline Single & 93.46 & 95.76 & 92.70 & 5.77 & 8.33 & 4.55 \\
\hline Married/Partner & 6.12 & 4.24 & 6.74 & 50.96 & 63.89 & 43.94 \\
\hline Divorced/Widowed & .42 & 0 & .56 & 43.27 & 27.78 & 51.52 \\
\hline \multicolumn{7}{|l|}{ Occupation (\%) } \\
\hline Working & 15.19 & 16.95 & 14.61 & 7.37 & 10.00 & 6.35 \\
\hline Student & 83.76 & 81.36 & 84.55 & 0 & 0 & 0 \\
\hline Not Working & 1.05 & 1.69 & .84 & 92.63 & 90.00 & 93.65 \\
\hline \multicolumn{7}{|l|}{ Rurality (\%) } \\
\hline Rural & 11.84 & 14.41 & 10.99 & 17.48 & 17.14 & 16.67 \\
\hline Small Town & 25.58 & 30.51 & 23.94 & 22.33 & 22.86 & 22.73 \\
\hline Town/Small City & 56.03 & 49.15 & 58.31 & 52.43 & 51.43 & 54.55 \\
\hline Large City & 6.55 & 5.93 & 6.76 & 7.77 & 8.57 & 6.06 \\
\hline \multicolumn{7}{|l|}{ Religious Activities } \\
\hline$<$ Once per month & 64.72 & 66.09 & 64.27 & 35.92 & 36.11 & 35.38 \\
\hline$\geq$ Once per month & 35.28 & 33.91 & 35.73 & 64.08 & 63.89 & 64.62 \\
\hline
\end{tabular}

Note. ${ }^{a}$ All younger adults were currently enrolled in an undergraduate course. Two older adults did not indicate their gender. 
Table 2

Descriptive Statistics for Study Variables

\begin{tabular}{llllllll}
\hline & \multicolumn{3}{c}{ Younger Adults } & & \multicolumn{2}{c}{ Older Adults } \\
Variable & Total & Men & Women & & $\frac{\text { Total }}{M(S D)}$ & Men & Women \\
\hline CES-D & $16.42(9.94)$ & $15.66(10.43)$ & $16.05(9.72)$ & & $12.10(8.46)$ & $11.38(8.46)$ & $12.58(8.62)$ \\
BIS-11 & $67.18(10.28)$ & $68.18(9.87)$ & $66.85(10.40)$ & & $59.14(11.06)$ & $56.79(11.27)$ & $60.30(10.79)$ \\
BIS-11 & $18.63(3.89)$ & $19.02(3.73)$ & $18.50(3.94)$ & & $15.15(4.22)$ & $14.55(3.83)$ & $15.46(4.45)$ \\
Att/Cog. & & & & & & & \\
SBQ-R & $4.72(2.60)$ & $4.97(2.94)$ & $4.64(2.47)$ & & $4.06(2.05)$ & $4.81(0.56)$ & $4.54(2.39)$ \\
& & & & & & & \\
\hline
\end{tabular}

\begin{tabular}{cccccc} 
Total & \multicolumn{3}{c}{ Men } & \multicolumn{2}{c}{ Women } \\
\hline$n$ & $\%$ & $n$ & $\%$ & $n$ & $\%$ \\
\hline
\end{tabular}

\begin{tabular}{llllll} 
Total & \multicolumn{3}{c}{ Men } & \multicolumn{2}{c}{ Women } \\
\hline$n$ & $\%$ & $n$ & $\%$ & $n$ & $\%$ \\
\hline
\end{tabular}

$\begin{array}{rcccccccccccc}\begin{array}{l}\text { Past Suicide } \\ \text { Attempt }\end{array} & 10 & 2.11 & 4 & 3.39 & 6 & 1.68 & 6 & 5.17 & 1 & 2.77 & 5 & 7.46 \\ \begin{array}{rllllllllll}\text { Intent Level } \\ \text { Low }\end{array} & 6 & 1.27 & 2 & 1.69 & 4 & 1.12 & 1 & 0.95 & 0 & 0 & 1 & 1.49 \\ \text { High } & 4 & 0.84 & 2 & 1.69 & 2 & 0.56 & 5 & 4.76 & 1 & 2.77 & 4 & 5.97\end{array}$

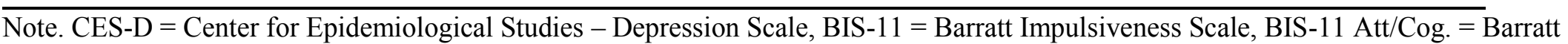
Impulsiveness Scale attentional/cognitive subscale, $\mathrm{SBQ}-\mathrm{R}=$ Suicidal Behaviors Questionnaire - Revised. SBQ-R is not transformed. 
Table 3

Intercorrelations among Study Variables and Means for All Participants $(N=579)$

\begin{tabular}{|c|c|c|c|c|c|c|}
\hline Measure & BIS & BIS Att/Cog. & CES-D & SBQ-R & Mean & $(S D)$ \\
\hline BIS & - & & & & 65.90 & $(10.80)$ \\
\hline BIS Cog/Att. & .80 & - & & & & \\
\hline CES-D & .26 & .34 & - & & 15.66 & $(9.83)$ \\
\hline SBQ-R & .15 & .18 & .47 & - & 4.60 & $(2.50)$ \\
\hline
\end{tabular}

Note. All correlations are significant $\mathrm{p}<.001 . \mathrm{CES}-\mathrm{D}=$ Center for Epidemiological Studies - Depression Scale, BIS-11 = Barratt Impulsiveness Scale, BIS-11 Cog/Att. = Barratt Impulsiveness Scale attentional/cognitive subscale, SBQ-R = Suicidal Behaviors Questionnaire - Revised Participant numbers for each correlation vary slightly due to missing data. SBQ-R is not transformed. 
Table 4

Intercorrelations among Study Variables for Younger $(n=474)$ and Older $(n=105)$ Adults

\begin{tabular}{lllll}
\hline Measure & BIS-11 & BIS-11 Att/Cog. & CES-D & SBQ-R \\
BIS-11 & - & .83 & .20 & .31 \\
BIS-11 Att.Cog. & .77 & - & .18 & .18 \\
CES-D & .23 & .33 & - & .41 \\
SBQ-R & .11 & .16 & .46 & - \\
\hline
\end{tabular}

Note. Intercorrelations for older adult participants are presented above the diagonal, and intercorrelations for younger adult participants are presented below the diagonal. Participant numbers for each correlation vary slightly due to missing data. SBQ-R is not transformed. 


\section{Appendix A.}

Suicidal Behaviors Questionnaire - Revised

In the previous sections, we have asked about some of your general thoughts and behaviors. The following questions ask about a specific topic - whether you have ever thoughts about suicide. Many people have had thoughts of suicide. Please answer honestly. Your responses will be kept confidential. Note: A list of mental health agencies available to help individuals having thoughts of suicide is included at the end of the survey.

Please circle one.

1. Have you ever thought about or attempted to kill yourself?
a. Never
b. It was a brief passing thought
c. I have had a plan at least once to kill myself but I did not want to try it
d. I have attempted to kill myself, but did not want to die
e. I have had a plan at least once to kill myself and really wanted to die
f. I have attempted to kill myself, and really hoped to die

2. How often have you thought about killing yourself in the past year?
a. Never
b. Rarely (1 time)
c. Sometimes (2 times)
d. Often (3-4 times)
e. Very often (5 or more times)

3. Have you ever told someone that you were going to commit suicide, or that you might do it? 

a. No
b. Yes, at one time, but did not really want to die
c. Yes, at one time and really wanted to die
d. Yes, more than once, but did not want to do it
e. Yes, more than once, and really wanted to do it
f. Yes, more than once, and really wanted to do it

4. How likely is it that you will attempt suicide someday?
a. Never
b. No chance at all
c. Rather unlikely
d. Unlikely
e. Likely
f. Rather Likely
g. Very Likely 
Appendix B.

Barratt Impulsiveness Scale

Listed below are the questions for this section of the survey. Please provide a response for every question.

Answer choices: 1 (Rarely/Never), 2, 3, 4 (Always/Almost Always)

1. I plan tasks carefully.*

2. I do things without thinking.

3. I make up my mind quickly,

4. I am happy-go-lucky.

5. I don't pay attention."

6. I have racing" thoughts.

7. I plan trips well ahead of time.*

8. I am self-controlled.*

9. I concentrate easily.*

10. I save regularly.*

11. I -squirm" at plays or lectures.

12. I am a careful thinker.*

13. I plan for job security.*

14. I say things without thinking.

15. I like to think about complex problems.*

16. I change jobs.

17. I act —on impsse."

18. I get easily bored when solving thought problems. 
19. I act on the spur of the moment.

20. I am a steady thinker.*

21. I change residences.

22. I buy things on impulse.

23. I can only think about one problem at a time.

24. I change hobbies.

25. I spend or charge more than I earn.

26. I often have extraneous thoughts when thinking.

27. I am more interested in the present than the future.

28. I am restless at the theater.

29. I like puzzles.*

30. I am future oriented.*

* reverse-scored 
Appendix C.

The Centers for Epidemiological Studies - Depression Scale

Below is a list of the ways you might have felt or behaved. Please check the boxes to tell me how often you have felt this way in the past week or so.

During the past week: Rarely or Not at all, Some of the Time, Occasionally, Most of the Time

1. I was bothered by things that don't usually bother me.

2. I did not feel like eating, my appetite was poor.

3. I felt that I could not shake the blues even with the help from my family and friends.

4. I felt that I was just as good as other people.*

5. I had trouble keeping my mind on what I was doing.

6. I felt depressed.

7. I felt that everything I did was an effort.

8. I felt hopeful about the future.*

9. I thought my life had been a failure.

10. I felt fearful.

11. My sleep was restless.

12. I was happy.*

13. I talked less than usual.

14. I felt lonely.

15. People were unfriendly.

16. I enjoyed life.*

17. I had crying spells.

18. I felt sad. 
19. I felt that people dislike me.

20. I could not zet going.”

*reverse scored 